\title{
Standard load conditions for sound levels measurement in portable saw operations: a proposed model
}

\begin{abstract}
The portable saw is a power tool widely used in industry for small cuts and finishes for floors, tiles, bricks and woods. It stands out for versatility, lightness and its ergonomics. The noise generated by this tool is high and may vary according to cutting material. This study proposes a standard load condition for sound levels measurement in operations of portable saw developed from standardized flat concrete slab that were prepared based on the characteristics of the materials commonly used in industry. The methodology compares noise generated during different load conditions and uncertainties measurements associated in operations of portable saw in accordance with ISO 3744: 2010, which specifies methods for determining sound power levels of noise sources by measuring the sound pressure for a plane essentially free. The standard deviation of reproducibility and of assembly conditions and operation are reported, according to criteria of expanded uncertainty measurement and conformity qualification. The standard load condition could help in quieter machines development as well as less disturbing, contributing with reduction of noise pollution and damage to the hearing health of workers in industry.
\end{abstract}

Keywords: standard load-measurement, noise-measurement, iso 3744, masonry saw, portable saw
Volume 2 Issue 2 - 2017

\begin{abstract}
Adriano AR Barbosa,' Stelamaris R Bertoli²
'Federal Institute of Sao Paulo, São Paulo, Brazil

${ }^{2}$ School of Civil Engineering, University of Campinas, São Paulo State, Brazil
\end{abstract}

Correspondence: AR Barbosa, Federal Institute of Sao Paulo, 450 R. Grande do Norte, Caraguatatuba, São Paulo, I I665-310, Brazil,Tel +55 (I2) 3885-2I30, Email adriano@ifsp.edu.br

Received: February 16, 2017 | Published: February 28, 2017

\section{Research highlights}

I. Proposes a standard load condition for sound levels measurement in operations of portable saw.

II. Behavior of portable saw during cutting is compared in different load conditions.

III. Comparative analysis considering uncertainties measurement in portable saw operations according with ISO 3744:2010.

\section{Introduction}

Construction noise, which is particularly annoying to society, has significant contributions from machines and tools. ${ }^{1}$ The United States Institute for Occupational Safety and Health states that about $90 \%$ of United States building workers are exposed to noise levels greater than $85 \mathrm{~dB}(\mathrm{~A}) .^{2}$ Builders seek new processes to reduce the time and labor costs of their work. However, mechanized construction is noisy, with the most powerful equipment often being the loudest. ${ }^{3}$ Hand-held electrical equipment is versatile and precise; there is a diverse range of such tools, and they are often inexpensive. They are widely used throughout construction industry. ${ }^{4}$

A full assessment of the noise conditions in a loud environment requires knowledge of the noise generated by each particular source. Equipment manufacturers usually provide values of the sound pressure levels measured at a set distance from their equipment. The sound pressure level depends on the conditions of the propagating sound, including the presence of obstacles. Various environmental factors can influence the spread of sound, such as temperature, pressure, and relative humidity. Besides the directivity and source position, the material being worked with can also affect the noise associated with certain equipment. The assessment of both ambient noise and noise from specific pieces of equipment at construction sites is important to the development of quieter practices. Masonry saws are louder when cutting materials than when running freely. ${ }^{4}$

ISO 3744:210 specifies methods for determining the sound power level of a noise source from sound pressure levels measured on a surface enveloping the noise source (machinery or equipment) in an environment that approximates to an acoustic free field near one or more reflecting planes. Information is given on the uncertainty of the sound power levels and sound energy levels determined in accordance with this International Standard, for measurements made in limited bands of frequency. The uncertainty conforms to ISO 12001:1996, accuracy grade 2 (engineering grade). ${ }^{5}$ This article presents a standard load condition for sound levels measurement in operations of portable saw according to ISO 3744:2010 developed from standardized flat concrete slab.

\section{Characteristics of portable saws}

Portable saws cut stone, concrete, masonry, ceramics, and glass. They are hand-held and portable. The average power of the motor is $1,400 \mathrm{~W}$ and the removable blade rotates at approximately $12,000 \mathrm{rpm}$. abrasive blade that is used with a masonry saw is a metal disk. Its cutting area is either continuous or segmented and set with industrial diamond crystals. ${ }^{6}$ Blades must comply with the standard set of specifications: $12.000-14.000 \mathrm{rpm}$ rotation; $110-125 \mathrm{~mm}$ diameter; $20 \mathrm{~mm}$ central bore; $1.4-1.6 \mathrm{~mm}$ thickness; $6-8 \mathrm{~mm}$ diamond height; $1.8-2.2 \mathrm{~mm}$ diamond thickness. ${ }^{6}$

\section{International standard ISO 3744:20 I 0}

The international standard ISO $3744: 2010$ is part of ISO 3740 series of standards for assessing sound levels. It specifies methods of measuring sound levels on a surface enveloping the noise source 
in an environment that approximates an acoustic free field over a reflecting plane. This standard aims determination of sound power levels from noise sources, such as machinery, equipment, and their sub-assemblies. The specified methodology requires assessment in the open air or a wide environment in which reflected energy does not significantly influence the energy radiated by the source. ${ }^{5}$

\section{Methodology}

The ISO 3744:2010 states that testing environments should be close to normal operating conditions to ensure the relevance of results. The measurement is conducted as stipulated by the standard; specific cutting conditions (i.e., a standard material to be cut) are proposed to allow the standardized assessment of masonry saws under conditions closely resembling those found during their regular use. To achieve an authentic simulation of regular use, the tests of this work were conducted while trained builders operated the masonry saws.

\section{Operations with masonry saws}

Masonry saws were used to perform common cutting tasks. The saws and diamond blades were new for the task, in accordance with current standards. The brands and models were readily commercially available and are often used at construction sites. Measurements were performed in an open area of a university campus; the floor was unpaved with some areas of trimmed grass; the surroundings were flat without sources of constructive interference and with low external noise.

\section{Measurements and materials}

Sound pressure levels of background noise were measured and compared with those of masonry saws running freely and while cutting cement slabs (the proposed standard load), ceramic plates, and slate. To ensure greater reproducibility of the assay, two types of standardized flat concrete slab were prepared based on the characteristics of the materials used. The cement slabs (dimensions $0.40 \times 0.40 \mathrm{~m}$, thickness 2 or $4 \mathrm{~cm}$ ) were fabricated by a technician using a specific composition of mortar made using a 1:2:0.45 volume ratio of Portland cement type II (moderate sulfate resistance), aggregate quartz sand with a specific gravity of $2.58 \mathrm{gcm}^{-3}$, and treated water. The clay slate and the ceramic plate used as comparative materials in the results of the sound levels obtained in this study are representative as load of cutting operation with portable saw, considering the different materials used in industry. ${ }^{7}$

\section{Equipment and measurement times}

Noise was measured using a sound level meter Brüel \& Kjær, model 2260. Sound pressure levels were measured with respect to frequency in $1 / 3$ octave bands between 100 and $10.000 \mathrm{~Hz}$. Each measurement was for $10 \mathrm{~s}$, in accordance with ISO 3744:2010.

\section{Measurement arrangement}

According to ISO 3744:2010, the radiation field and the minimum dimensions of the test environment must be arranged such that the measurement points can be described as occupying certain points on the faces of a cuboid-shaped measurement surface. Figure 1 illustrates the measurement points and their physical arrangement. The hatched area denotes the reflector plane; the central shaded box represents the noise source located under a reflecting plane. The standard states that six measurements must be performed during each operation of the machine (L'pi (ST)) at each point in the measurement surface.

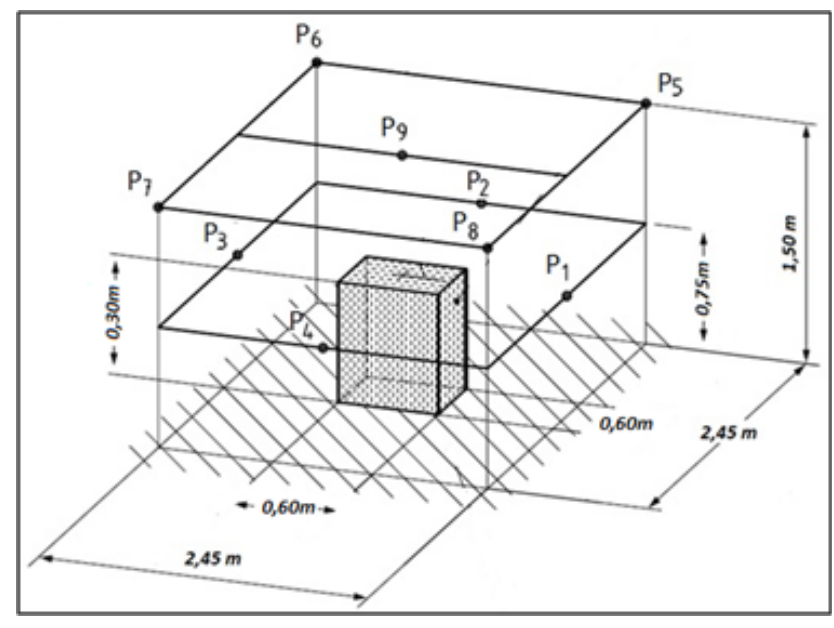

Figure I Measurement arrangement.

\section{Calculations}

The surface time-averaged sound pressure level, $L p$, shall be calculated by correcting the mean time-averaged sound pressure level, $L_{p}^{\prime}(\mathrm{ST})$, for background noise $\left(K_{1}\right)$ and for the influence of the test environment $\left(K_{2}\right)$ using Equation (3):

$$
\bar{L}_{p}=\overline{L_{p(\mathrm{ST})}}-K_{1}-K_{2}
$$

According to ISO 3744: 2010, from the estimated total standard deviation $\sigma_{\text {tot }}$ the measurement uncertainty was determined as follows:

$$
u\left(L_{\text {wref, atm }}\right) \approx \sigma_{\text {tot }}=\sqrt{\sigma^{2} R o}+\sigma^{2} \text { omc }=\sqrt{\sum_{i}\left(c_{i} u_{i}\right)^{2}}+\sigma^{2} \text { omc }
$$

Where:

$\sigma_{\text {tot }}:$ estimated total standard deviation.

$\sigma_{\text {omc }}:$ deviation from uncertainties, instability of operation and assembly conditions.

$\sigma_{\mathrm{R} 0}:$ deviation corrected for environmental uncertainties and test conditions.

$\mathrm{C}_{\mathrm{i}}$ : sensitivity coefficient of the $\mathrm{i}-\mathrm{th}$ component of the deviation
$\sigma_{\mathrm{R} 0}$.

$u_{i}:$ standard uncertainty of the $\mathrm{i}$-th component of the deviation $\sigma_{\mathrm{R} 0}$.

The measurement uncertainty used in ISO 3744: 2010 is determined by the expanded measurement uncertainty $U$, which is derived directly from the total standard deviation $\sigma_{\text {tot }}$ being the approximation of the relevant $\mathrm{u}\left(\mathrm{L}_{\mathrm{w}}\right)$ as defined in the ISO/IEC Guide 98-3. This total standard deviation, $\sigma_{\text {tot }}$, results from the two components $\sigma_{\mathrm{RO}}$ and $\sigma_{\text {omc }}$.

Derived from $\sigma_{\text {tot }}$, calculate the expanded measurement uncertainty $\mathrm{U}$, in decibels

$$
\mathrm{U}=\mathrm{k} \cdot \sigma_{\mathrm{tot}}
$$

The uncertainty of measurement depends on the degree of confidence desired. ISO 3744: 2010 recommends that for a normal distribution of measurement values there is $95 \%$ confidence that the true value will lie within a range corresponding to a range factor of $k=2$. 


\section{Result}

The expanded measurement uncertainty (U) with respect to frequency, resulting from all the magnitudes associated with the operations of portable saw in the sound level measurement tests, under different load conditions in an open field on the reflecting plane is represented in Figure 2. Presented also the mean expanded measurement uncertainty and the standard deviation.

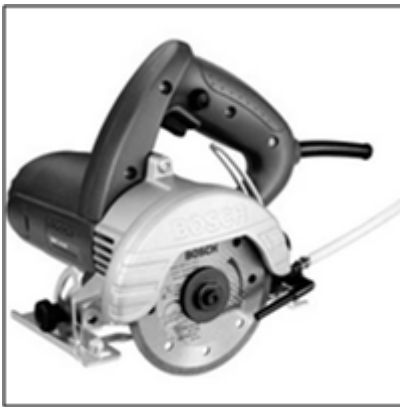

(a)

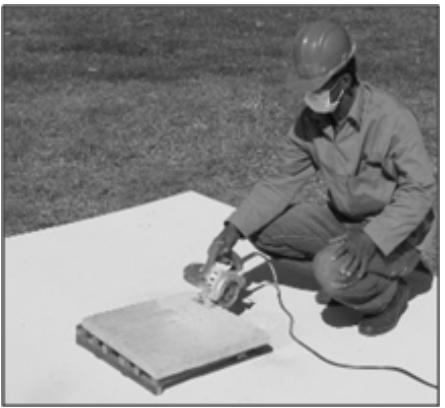

(b)
Figure 2 (a) The tested masonry saw, (b) its use in an open field over a plane.

For the calculation of the expanded uncertainty measurement (U), a normal range factor $(K=2)$ was adopted which corresponds to $95 \%$ confidence that the true value lies within the range used. Figure 3 shows that the value of the deviation to be considered for the analysis of sound power uncertainties $\left(\mathrm{L}_{\mathrm{w}}\right)$ from the measurements and calculations performed according to ISO 3744: 2010, in the frequencies of $1 \mathrm{~K}$ to $10 \mathrm{KHz}$, is $\mathrm{U}=4.3 \mathrm{~dB}$.

According to ISO Standard 3744: 2010, measurement uncertainty depends on the degree of confidence desired. Considering the test conditions presented, the distribution of the sound power values $\left[\mathrm{L}_{\mathrm{w}}\right]$ is within the range $\left[\mathrm{L}_{\mathrm{w}}-\mathrm{U}\right]$ to $\left[\mathrm{L}_{\mathrm{w}}+\mathrm{U}\right]$. Figure 4 shows the sound power levels $\left(\mathrm{L}_{\mathrm{w}}\right)$ related to the ranges of uncertainty.

It is observed in figure 4 that uncertainty measurement interval representing the standard load of $2 \mathrm{~cm}$ is lower than the others, which points out that its maximum value of sound power level, in the interval $\left[\mathrm{L}_{\mathrm{W}}+\mathrm{U}\right]$, has reached to $109.9 \mathrm{~dB}$, and this represents a value below the average of the level obtained by cutting clay slate $(110.1 \mathrm{~dB})$ and close result for cutting the ceramic plate $(109 \mathrm{~dB})$. It can be stated that $39.5 \%$ of the interval, in the uncertainty of the standard load of $2 \mathrm{~cm}$, are within the range corresponding to the slate and ceramic plate together, while for the load of $4 \mathrm{~cm}$ this value reaches $93.3 \%$, thus indicating greater similarity in the range of the sound power level $\left[\mathrm{L}_{\mathrm{w}}-\mathrm{U}\right]$ to $\left[\mathrm{L}_{\mathrm{w}}\right.$ $+\mathrm{U}]$ of the standard load of $4 \mathrm{~cm}$, when compared to these materials. It was observed, however, that the values of the standard deviation of the global sound power levels of the load of $4 \mathrm{~cm}(=0,9 \mathrm{~dB})$ and load of $2 \mathrm{~cm}(\sigma=2,3 \mathrm{~dB})$ are within the margin considered in this study $(\mathrm{U}=4.3 \mathrm{~dB})$. Thus, in the analysis of the uncertainty of measurement in the results of the sound power levels, it is stated that both loads $(2 \mathrm{~cm}$ and $4 \mathrm{~cm}$ ) met the criteria of the expanded measurement uncertainty, being able to qualify them as conforming according to the Standard ISO 3744: 2010.

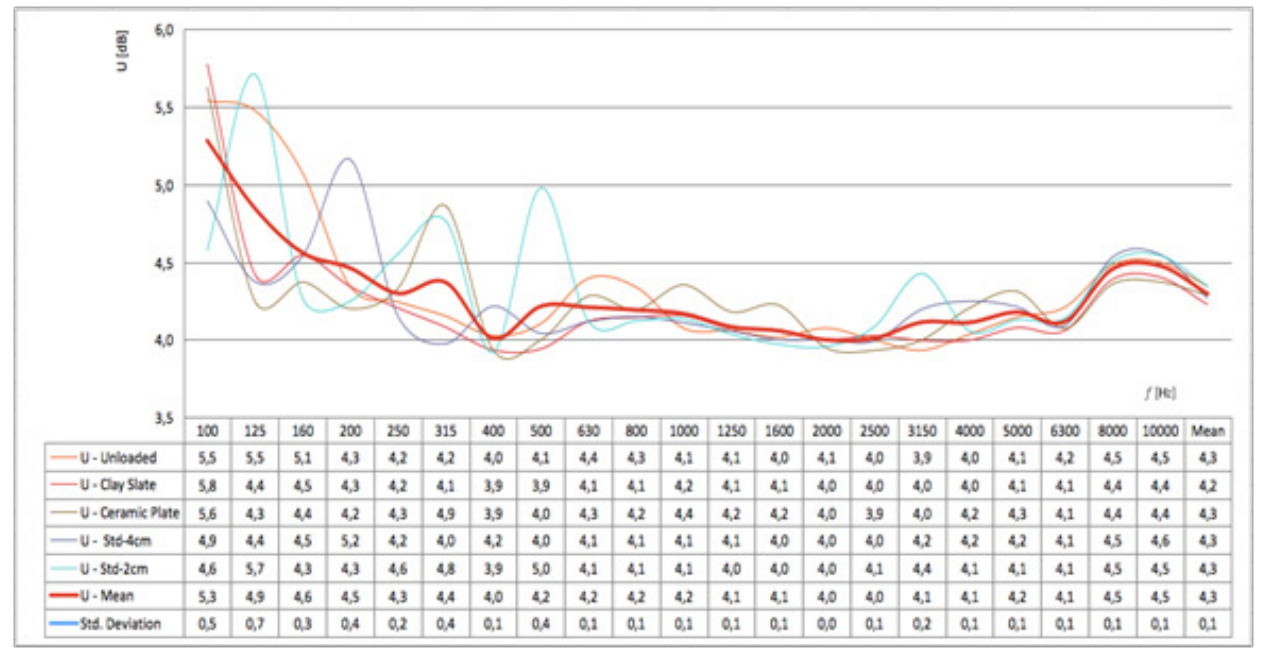

Figure 3 Expanded measurement uncertainty $(U)$ under load conditions, mean and standard deviation.

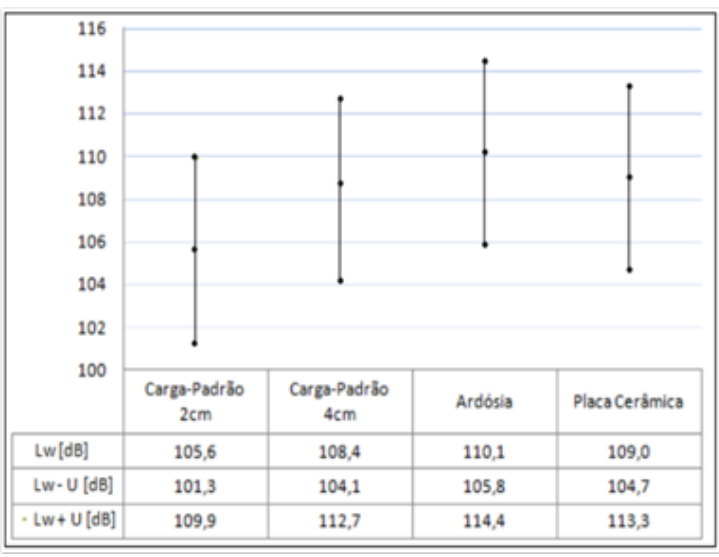

Figure 4 Sound power level $[\mathrm{Lw}]$ and expanded uncertainty measurement intervals [U].

\section{Conclusion}

The results obtained in this study, from the test procedures according to ISO, from the sound power level generated by portable saw with different load conditions, considering the associated measurement uncertainties, allowed to validate the proposed standard load on operations of this nature. The standard loads proposed in this study were standard cement boards for confection in laboratories, measuring $40 \times 40 \mathrm{~cm}$, with $2 \mathrm{~cm}$ and $4 \mathrm{~cm}$ thickness. Elements made with basic and internationally used building materials. It was shown to be easy to prepare and mold, making it possible to use it as a loading condition in tests to determine sound levels with portable saw. The overall values of the sound levels of the proposed standard loads were very close to those generated by reference materials. The standard loads (cement slabs) represented, in the cutting operations, the sound levels generated according to those obtained at construction sites, in cutting operations with the portable saw. 
As proposals for future work, it is suggested: relating the physical characteristics of the materials with the cutting noise generated; Propose an automated device to replace the operator with the particular sensitivity and handling of the saw; Study of the vibration behavior of plates, resonance frequencies, harmonics series generated and its interference with the generated noise; Investigation of sound power by acoustic intensimetry. This study of standard load condition contributes to facilitate the assembly and to guarantee greater reproducibility in the tests of measurement of the sound levels in the operations with portable saw and could help in quieter machines development as well as less disturbing, contributing with reduction of noise pollution and damage to the hearing of workers in industry.

\section{Acknowledgements}

None.

\section{Conflict of interest}

The author declares no conflict of interest.

\section{References}

1. Ballesteros MJ, Fernández MD, Quintana S, et al. Noise emission evolution on construction sites. Measurement for controlling and assessing its impact on the people and on the environment. Building and Environment Journal. 2010;45(3):711-717.
2. NIOSH-National Institute for Occupational Safety and Health. Occupational noise exposure-revised criteria 2011. Ohio: US Department of Health and Human Services.

3. Seixas NS, Neitzel R, Stover B, et al. 10-Year prospective study of noise exposure and hearing damage among construction workers. Occupational \& Environmental Medicine Journal. 2012;69:643-650.

4. Barbosa AAR, Bertoli SR. Noise Generated by Portable Saw in Different Construction Materials. American Journal of Civil Engineering and Architecture. 2017;5(1):17-24.

5. International Organization for Standardization. ISO 3744-AcousticsDetermination of sound power levels of noise sources using sound pressure: Engineering methods for an essentially free field over a reflecting plane. Switzerland; 2010.

6. Brazilian Association of Technical Standards-ABNT NBR 15910: 2010 Tools portable electric motor operated-Safety: Particular requirements for masonry saw. 2010. 15 p.

7. Barbosa AAR, Bertoli SR. Noise generated by masonry saws in Brazilian construction materials. In: 44 ${ }^{\text {th }}$ International Congress and Exposition on Noise Control Engineering (Internoise), 2015, San Francisco, CA. Implementing Noise Control Technology. NY: Curran Associates; 2015. p. $5856-5860$. 